\title{
Reduction of Food Intake by Fenofibrate is Associated with Cholecystokinin Release in Long-Evans Tokushima Rats
}

\author{
Mi-Kyoung Park ${ }^{1}$, Ying Han ${ }^{1,2}$, Mi Sun Kim ${ }^{1,2}$, Eunhui Seo ${ }^{2}$, Soojeong Kang ${ }^{2}$, So-Young Park ${ }^{2}$, Hyeongjong \\ $\mathrm{Koh}^{2}$, Duk Kyu Kim ${ }^{1}$, and Hye-Jeong Lee ${ }^{2}$ \\ Departments of ${ }^{1}$ Internal Medicine and ${ }^{2}$ Pharmacology, Medical Science Research Center, Mitochondria Hub Regulation Center, Dong-A \\ University College of Medicine, Busan 602-714, Korea
}

\begin{abstract}
Fenofibrate is a selective peroxisome proliferator-activated receptor $\alpha(\operatorname{PPAR} \alpha)$ activator and is prescribed to treat hyperlipidemia. The mechanism through which PPAR $\alpha$ agonists reduce food intake, body weight, and adiposity remains unclear. One explanation for the reduction of food intake is that fenofibrate promotes fatty acid oxidation and increases the production of ketone bodies upon a standard experimental dose of the drug $(100 \sim 300 \mathrm{mg} / \mathrm{kg} /$ day $)$. We observed that low-dose treatment of fenofibrate $(30 \mathrm{mg} / \mathrm{kg} / \mathrm{day})$, which does not cause significant changes in ketone body synthesis, reduced food intake in Long-Evans Tokushima (LETO) rats. LETO rats are the physiologically normal controls for Otsuka Long-Evans Tokushima Fatty (OLETF) rats, which are obese and cholecystokinin (CCK)-A receptor deficient. We hypothesized that the reduced food intake by fenofibrate-treated LETO rats may be associated with CCK production. To investigate the anorexic effects of fenofibrate in vivo and to determine whether CCK production may be involved, we examined the amount of food intake and CCK production. Fenofibrate-treated OLETF rats did not significantly change their food intake while LETO rats decreased their food intake. Treatment of fenofibrate increased CCK synthesis in the duodenal epithelial cells of both LETO and OLETF rats. The absence of a change in the food intake of OLETF rats, despite the increase in CCK production, may be explained by the absence of CCK-A receptors. Contrary to the OLETF rats, LETO rats, which have normal CCK receptors, presented a decrease in food intake and an increase in CCK production. These results suggest that reduced food intake by fenofibrate treatment may be associated with CCK production.
\end{abstract}

Key Words: Fenofibrate, Cholecystokinin, Food intake, LETO rat, OLETF rat

\section{INTRODUCTION}

Fenofibrate is currently used to control lipid abnormalities in dyslipidemic humans [1] and acts as a peroxisome proliferator-activated receptor $\alpha(\operatorname{PPAR} \alpha)$ ligand that regulates the expression of a number of genes that are important in lipid and glucose metabolism. Recently, several studies have examined the effects of PPAR $\alpha$ agonists on energy intake, body weight, and body fat in rodent models of obesity. In selectively bred obese-prone rats, fenofibrate $(100 \mathrm{mg} / \mathrm{kg}$ per day) reduced body weight gain, adiposity, food intake, and feed efficiency [2]. Dietary fenofibrate (100 $\mathrm{mg} / \mathrm{kg}$ per day) also reduced the food intake, body weight,

Received February 28, 2012, Revised May 3, 2012,

Accepted May 29, 2012

Corresponding to: Hye-Jeong Lee, Department of Pharmacology, Dong-A University College of Medicine, Dongdaeshin-dong, Seo-gu, Busan 602-714, Korea. (Tel) 82-51-240-2859, (Fax) 82-51-241-0778, (E-mail) hjlee@dau.ac.kr

(1) (8) This is an Open Access article distributed under the terms of the Creative Commons Attribution Non-Commercial License (http: $/$ Creative Commons Attribution Non-Commercial License (http// creativecommons.org/licenses/by-nc/3.0) which permits unrestricted non-commercial use, distribution, and reproduction in any medium, provided the original work is properly cited. and adiposity of obese Otsuka Long-Evans Tokushima Fatty (OLETF) rats [3]. In $\mathrm{db} / \mathrm{db}$ mice, fenofibrate $(0.2 \%, \mathrm{w} / \mathrm{w})$ treatment was associated with decreased food intake [4]. Even though the mechanism of decreased food intake by fenofibrate has not been established, several reports demonstrate that $\operatorname{PPAR} \alpha$ agonists promote fatty acid oxidation and increase ketone body production [5-7]. When the ketone body, beta-hydroxybutyrate, was administered peripherally $[8,9]$ or centrally [10], it produced a decrease in food intake. These results suggest that fenofibrate may decrease food intake due to ketogenesis via increased fatty acid oxidation.

However, we observed that a low-dose treatment of fenofibrate $(30 \mathrm{mg} / \mathrm{kg} / \mathrm{day})$, which does not increase ketone body production, decreased the amount of food intake in LongEvans Tokushima (LETO) rats, which are the physiologically normal counterparts of OLETF rats. In contrast, OLETF rats, which are defective in cholecystokinin (CCK)A receptors, did not show any change in food intake with the low-dose treatment of fenofibrate. This observation may indicate that CCK plays a role in reducing food intake when fenofibrate, which does not increase the plasma level of ke-

ABBREVIATIONS: $\operatorname{PPAR} \alpha$, peroxisome proliferator-activated receptor $\alpha$; CCK, cholecystokinin; LETO, Long-Evans Tokushima; OLETF, Otsuka Long-Evans Tokushima Fatty. 
tone bodies, is administered in a low dose.

CCK is a hormone that is secreted from duodenal and jejunal mucosal cells in response to fat and protein [11]. CCK has a number of physiological effects, such as slowing gastric emptying, modulating gastrointestinal motility and suppressing energy intake [12]. The postprandial satiety may be attributed predominantly to the CCK released in the gut and acting via the vago-vagal reflex rather than directly on the satiety center in CNS [13]. There are two receptors for CCK, CCK-A (CCK1r) and CCK-B (CCK2r). OLETF rats genetically lack CCK-A receptors as a result of a mutation [14]. The tubby mouse which is decreased with the expression of CCK-B receptor is characterized by progressive retinal and cochlear degeneration and late-onset obesity [15]. OLETF rats consume much larger meals and are completely resistant to the inhibitory effects of exogenous CCK, as well as gastric or intestinal nutrient infusion, upon energy intake [16]. To examine the relationship between fenofibrate and CCK, OLETF rats can be used as an experimental model in place of CCK receptor-deficient rats.

In the present study, we hypothesized that the anorexigenic mechanism of fenofibrate may be associated with the induction of CCK. We found that fenofibrate increases the synthesis of CCK and that CCK induction by fenofibrate does not affect the appetite of CCK receptor-deficient OLETF rats. These results suggest that CCK induction may be associated with one of the anorexigenic mechanisms caused by fenofibrate.

\section{METHODS}

\section{Animals and treatment}

Ten-week-old male LETO $(\mathrm{n}=10)$ and OLETF $(\mathrm{n}=10)$ rats were kindly donated by Otsuka Pharmaceutical (Tokushima, Japan). The rats were kept in individual cages in an environmentally controlled room in Dong-A University Animal Care Center with free access to water and standard rat chow during the experimental period. When the rats were 17 weeks old, LETO rats were divided into two groups. The LETO-fenofibrate group $(n=5)$ was fed with standard rat chow and fenofibrate (Laboratoires Fournier, Green Cross, South Korea) (30 mg/kg/day) for 11 weeks. The LETO-control group $(n=5)$ was only fed with standard rat chow for the same period. The OLETF rats were also divided into an OLETF-fenofibrate group (30 mg/kg/day) $(\mathrm{n}=5)$ and an OLETF-control group $(n=5)$. For the entire period of the experiment, all rats were cared for under the Guidelines of Animal Experiments recommended by the Korean Academy of Medical Sciences. We measured the daily food intake and body weight of all rats by weighing the special food containers and the cages of the rats at regular intervals. After 18 hours of fasting, blood was drawn from the tail vein to measure fasting blood sugar (FBS) and plasma levels of leptin and $\beta$-ketone. At 28 weeks of age, all rats were anesthetized and sacrificed for further analysis.

\section{Measurement of fasting blood sugar, ketone, and leptin levels}

FBS levels were measured with GlucoDr (Allmedicus, Seoul, South Korea). Blood $\beta$-ketone levels were measured with MediSense Optium (Abbott Laboratories, Abbott Park, IL). Plasma leptin levels were analyzed with a rat leptin
ELISA kit (Linco Research, St. Charles, MO).

\section{Real-time PCR analysis}

Total RNA was isolated with Trizol reagent (Invitrogen, Carlsbad, CA), and single-strand cDNA was synthesized from $2 \mu \mathrm{g}$ of total RNA with Oligo(dT)15 Primer, M-MLV Reverse Transcriptase, M-MLV 5X reaction buffer, dNTP and ribonuclease inhibitor (Promega, Madison, WI). Realtime PCR analyses were performed using an ABI PRISM 7000 Sequence Detection System (Applied Biosystems, Foster city, CA). Each reaction was carried out with 12.5 $\mu \mathrm{l}$ of $2 \mathrm{X}$ SYBR master mix, $1 \mu \mathrm{l}$ of cDNA, 2.5 $\mu \mathrm{l}$ of $3 \mu \mathrm{M}$ forward and reverse primers, and $6.5 \mu \mathrm{l}$ of water. The experiments were performed in triplicate, and $18 \mathrm{~S}$ RNA was used as the invariant control for all studies.

\section{PPAR $\alpha$ agonists treatment of Caco-2 cells}

A human intestinal epithelial cell line, Caco-2 [17], was purchased from Korean Cell Line Bank (Seoul, South Korea) and was maintained in Minimum Essential Medium (Invitrogen) with $10 \%$ of Fetal Bovine Serum (ThermoFisher Scientific, Waltham, MA) and 1\% of Penicillin/Streptomycin (Invitrogen) at $37^{\circ} \mathrm{C}$ in a humidified incubator with $5 \% \mathrm{CO}_{2}$. The Caco-2 cells were cultured in the presence of fenofibrate, bezafibrate or clofibrate (Sigma-Aldrich, St. Louis, MO) for 24 hours.

\section{Measurement of PPAR $\alpha$ and CCK expression}

Total proteins were isolated from Caco-2 cells and the small intestine of rats using radioimmunoprecipitation assay buffer containing Protease Inhibitor Cocktail and Phosphatase Inhibitor Cocktails (Sigma-Aldrich). Protein concentration was determined in triplicate using the bicinchronic acid solution with copper sulfate solution (SigmaAldrich). Protein samples were mixed with Laemmli Sample Buffer and placed in a boiling water bath for $5 \mathrm{~min}$. Proteins were resolved in an $8 \sim 12 \%$ SDS-polyacrylamide gel electrophoresis (SDS-PAGE; equal amounts of total protein were loaded in each lane) and transferred to nitrocellulose membranes. Blots were probed with antibodies to $\operatorname{PPAR} \alpha, \mathrm{CCK}$, and $\beta$-actin (Santa Cruz Biotechnology, Santa Cruz, CA). Blots were developed using horseradish peroxidase-conjugated secondary antibodies, followed by incubation with ECL Plus Western Blotting Detection Reagents (Amersham, UK), and signals were detected using a Fuji LAS 4000 Imaging station (Tokyo, Japan).

\section{Statistical analysis}

All the results are expressed as means \pm SE. Significance of differences between groups were analyzed by Student's $t$-test and a one-way ANOVA. We used statistical programs in SPSS 9.0 for Windows. Differences were considered significant when a $\mathrm{p}$ value was less than 0.05 .

\section{RESULTS}

\section{Effects of low-dose fenofibrate on daily food intake and} body weight

Low-dose $(30 \mathrm{mg} / \mathrm{kg} /$ day $)$ treatment of fenofibrate signifi- 
cantly reduced the amount of food intake in LETO rats starting at 4 weeks after treatment (Fig. 1A). The average amount of food intake by the control group of LETO rats was $27 \pm 1 \mathrm{~g} /$ day while that of the fenofibrate group was significantly decreased to $24 \pm 1$ g/day $(\mathrm{p}<0.05)$. In hyperphagic OLETF rats, however, the food intake of the fenofibratetreated group ( $35 \pm 1 \mathrm{~g} /$ day) was not significantly different from that of the control group ( $35 \pm 2 \mathrm{~g} /$ day) (Fig. 1A).

After the experimental period of 11 weeks, the body weight of LETO rats increased from $457 \pm 21 \mathrm{~g}$ to $512 \pm 30$ $\mathrm{g}$ in the fenofibrate group and from $455 \pm 19 \mathrm{~g}$ to $517 \pm 31$ $\mathrm{g}$ in the control group of LETO rats. In OLETF rats, the body weight of the fenofibrate group increased from $587 \pm 30$ $\mathrm{g}$ to $690 \pm 36 \mathrm{~g}$, and that of the control group increased from $587 \pm 28 \mathrm{~g}$ to $700 \pm 33 \mathrm{~g}$. The increase in body weight was gained over the experimental period (Fig. 1B).

\section{Effects of low-dose fenofibrate on metabolic parameters}

Fenofibrate had no effect on the FBS levels of LETO rats $(114 \pm 19 \mathrm{mg} / \mathrm{dl}$ vs. $125 \pm 13 \mathrm{mg} / \mathrm{dl}$; control vs. fenofibrate) (Table 1). The FBS levels in the fenofibrate group of OLETF rats seemed to decrease after the fenofibrate treatment $(162 \pm 16 \mathrm{mg} / \mathrm{dl}$ vs. $153 \pm 23 \mathrm{mg} / \mathrm{dl}$, control vs. fenofibrate), but there was no statistical difference. The blood $\beta$-ketone level in the fenofibrate group of LETO rats was $1.0 \pm 0.3 \mathrm{mmol} / \mathrm{l}$
A
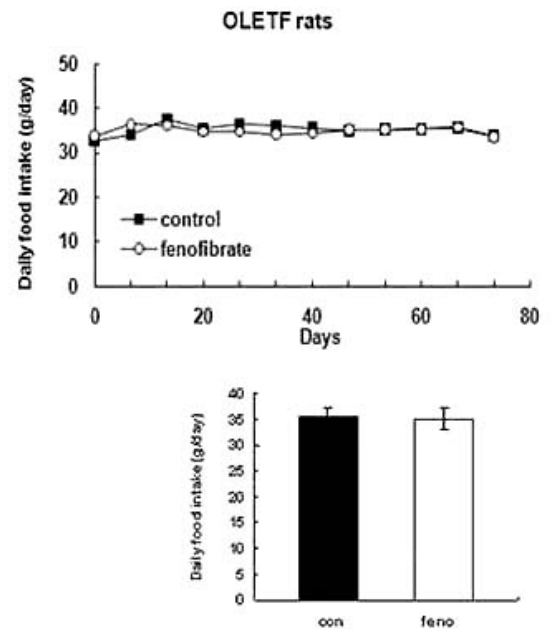

B

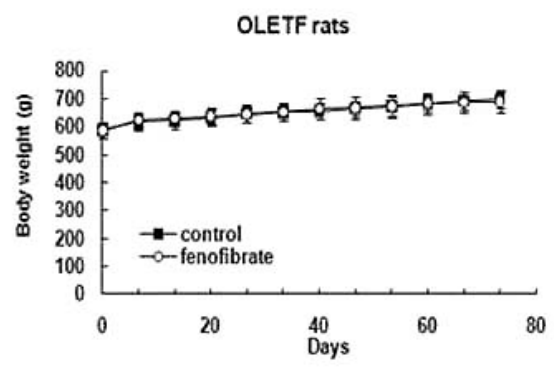

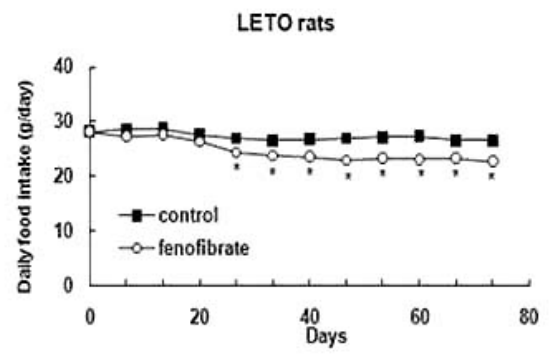
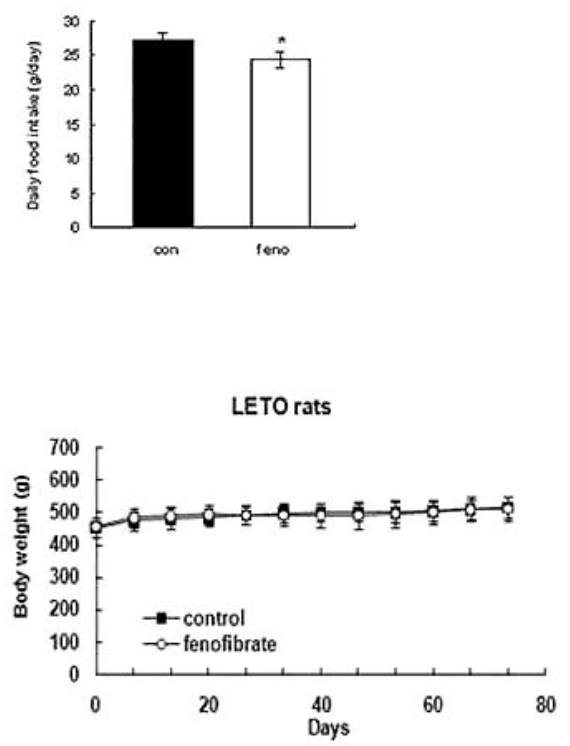

Fig. 1. Change of food consumption (A) and body weight gain (B) in LETO and OLETF rats. In LETO rats, the average consumption of the control group was $27 \pm 1$ g per day while the average consumption of the fenofibrate group was $24 \pm 1 \mathrm{~g}$ per day $(p<0.05)$. Values are means \pm SEM. $\mathrm{n}=5$.

Table 1. Metabolic parameters

\begin{tabular}{|c|c|c|c|c|c|c|c|c|}
\hline & \multicolumn{4}{|c|}{ LETO } & \multicolumn{4}{|c|}{ OLETF } \\
\hline & \multicolumn{2}{|c|}{ Before treatment $(0 \mathrm{w})$} & \multicolumn{2}{|c|}{ After treatment $(11 \mathrm{w})$} & \multicolumn{2}{|c|}{ Before treatment $(0 \mathrm{w})$} & \multicolumn{2}{|c|}{ After treatment $(11 \mathrm{w})$} \\
\hline & Con & Feno & Con & Feno & Con & Feno & Con & Feno \\
\hline FBS (mg/dl) & $128 \pm 11$ & $136 \pm 11$ & $114 \pm 19$ & $125 \pm 13$ & $170 \pm 6$ & $186 \pm 40$ & $162 \pm 16$ & $153 \pm 23$ \\
\hline$\beta$-ketone $(\mathrm{mmol} / \mathrm{l})$ & $1.0 \pm 0.2$ & $1.0 \pm 0.3$ & $0.8 \pm 0.3$ & $1.0 \pm 0.3$ & $0.4 \pm 0.1$ & $0.3 \pm 0.1$ & $0.7 \pm 0.4$ & $0.5 \pm 0.3$ \\
\hline Leptin (ng/ml) & $0.10 \pm 0.04$ & $0.11 \pm 0.03$ & $0.31 \pm 0.09$ & $0.24 \pm 0.08$ & $0.81 \pm 0.22$ & $1.03 \pm 0.29$ & $1.36 \pm 0.10$ & $1.36 \pm 0.37$ \\
\hline Liver weight (g) & NA & NA & $13.0 \pm 1.2$ & $16.1 \pm 1.6^{*}$ & NA & NA & $22.2 \pm 4.0$ & $25.7 \pm 1.3^{*}$ \\
\hline
\end{tabular}

Data are presented as means \pm SEM for $n=5$ rats. ${ }^{*} p<0.05$ vs. control of $11 \mathrm{w}$ after treatment. Con, control; Feno, fenofibrate treatment; FBS, fasting blood sugar; NA, nonavailable. 
and it was not significantly different from that of the control group $(0.8 \pm 0.3 \mathrm{mmol} / \mathrm{l})$. Among the OLETF rats, there was also no significant difference between the fenofibrate $(0.5 \pm 0.3 \mathrm{mmol} / \mathrm{l})$ and the control $(0.7 \pm 0.4 \mathrm{mmol} / \mathrm{l})$ group (Table 1). After 11 weeks of fenofibrate treatment, the plasma leptin levels of the fenofibrate group of LETO rats tended to be lower than that of the control group $(0.31 \pm 0.09$ $\mathrm{ng} / \mathrm{ml}$ vs. $0.24 \pm 0.08 \mathrm{ng} / \mathrm{ml}$, control vs. fenofibrate), but there was no statistical significance (Table 1). In OLETF rats, there was no significant difference in the plasma leptin levels between the fenofibrate and the control group after fenofibrate treatment $(1.36 \pm 0.10 \mathrm{ng} / \mathrm{ml}$ vs. $1.36 \pm 0.37 \mathrm{ng} / \mathrm{ml}$, control vs. fenofibrate). The average liver weight of the fenofibrate group was significantly increased compared with that of the control group both in LETO $(13.0 \pm 1.2 \mathrm{~g}$ vs. $16.1 \pm 1.6$ $\mathrm{g}$, control vs. fenofibrate, $\mathrm{p}<0.05)$ and OLETF rats $(22.2 \pm$ $4.0 \mathrm{~g}$ vs. $25.7 \pm 1.3 \mathrm{~g}$, control vs. fenofibrate, $\mathrm{p}<0.05)$ after 11 weeks of fenofibrate treatment.

\section{Effects of low-dose fenofibrate on intestinal PPAR $\alpha$ and $C C K$}

To understand the physiological mechanism by which fenofibrate reduced food intake, we examined the effects of fenofibrate on the expression levels of $\operatorname{PPAR} \alpha$ and CCK in the small intestines of LETO and OLETF rats. Surprisingly, the mRNA expression of CCK was markedly increased by fenofibrate treatment, and the expression of $\operatorname{PPAR} \alpha$ was increased in the small intestine of LETO rats (Fig. 2A). The protein level expressions of CCK and $\operatorname{PPAR} \alpha$ were also in-

\section{A}
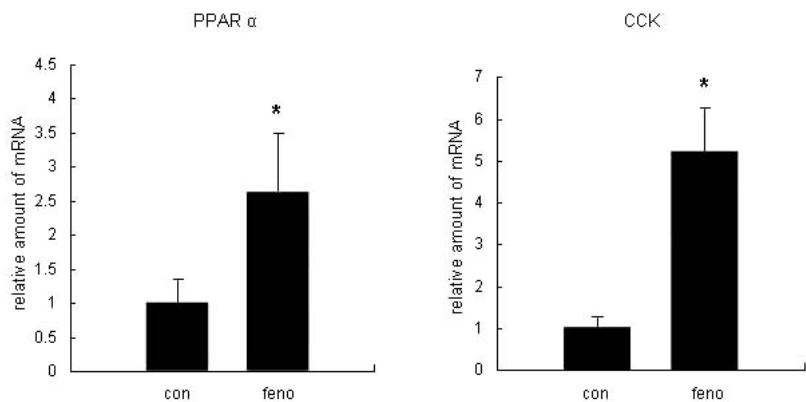

B

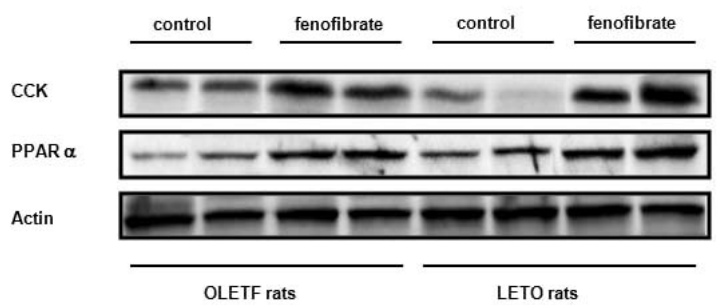

Fig. 2. Effects of fenofibrate on the expression of PPAR $\alpha$ and CCK in the small intestines of LETO and OLETF rats. (A) Relative amounts of PPAR $\alpha$ and CCK mRNA were analyzed by RT-PCR in the small intestine of LETO rats. Values shown (means \pm SEM) are normalized against GAPDH mRNA. $n=5$. ${ }^{*} \mathrm{p}<0.05$ vs. control. (B) Protein levels of PPAR $\alpha$ and CCK were analyzed by western blotting. creased by fenofibrate treatment in the small intestines of OLETF and LETO rats (Fig. 2B).

\section{Effects of PPAR a agonists on Caco-2 cells}

To explore whether fenofibrate induces CCK expression at the cellular level of human intestine, we employed Caco- 2 cells, a human intestinal epithelial cell line. Lowdose treatment of fenofibrate increased the expression of CCK dose-dependently (Fig. 3A). In addition, the expression of $\operatorname{PPAR} \alpha$ was increased by the fenofibrate treatment in Caco-2 intestinal cells. To examine whether the induction of the CCK expression was a unique effect of fenofibrate, we tested other kinds of $\operatorname{PPAR} \alpha$ agonists such as bezafibrate and clofibrate. The expression of CCK in Caco- 2 cells was also induced by bezafibrate and clofibrate (Fig. 3B). All three $\operatorname{PPAR} \alpha$ agonists increased the protein levels of CCK and PPAR $\alpha$ in Caco- 2 cells.

\section{DISCUSSION}

The usual experimental dose (high dose, $100 \sim 300 \mathrm{mg} / \mathrm{kg}$ ) treatment of fenofibrate increases blood levels of $\beta$-ketone $[2,5,6]$ and decreases food intake $[3,4,18]$. In the present low-dose study, the blood $\beta$-ketone level in the fenofibrate group of LETO rats was not significantly different from that of the control group. The level of OLETF rats seems to be slightly lower compared to LETO rats, but the normal range of blood $\beta$-ketone level is below $1.0 \mathrm{mmol} / \mathrm{l}$. The plasma leptin level of OLETF rats shows higher than LETO rats because the body weight of OLETF rats is higher. After 11 weeks of fenofibrate treatment, the plasma leptin levels of the fenofibrate group of LETO rats tended to be lower
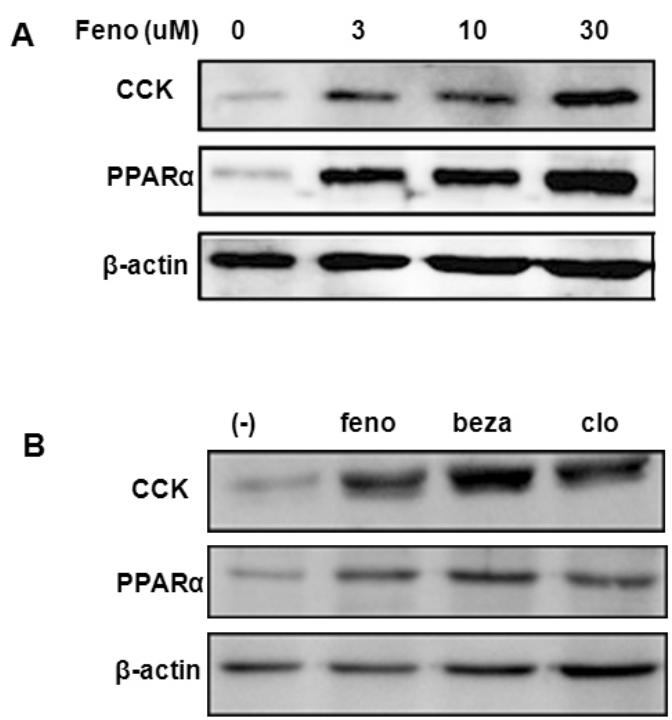

Fig. 3. Effects of fenofibrate on the expression of $\operatorname{PPAR} \alpha$ and CCK in Caco-2 cells. (A) The expression of CCK increased dosedependently with a low-dose treatment of fenofibrate $(3,10$ and $30 \mu \mathrm{M}$ ) for $24 \mathrm{~h}$. (B) The expression of CCK in Caco- 2 cells was induced by several kinds of $\operatorname{PPAR} \alpha$ agonists; fenofibrate $100 \mu \mathrm{M}$ (feno), bezafibrate $100 \mu \mathrm{M}$ (beza) and clofibrate $250 \mu \mathrm{M}$ (clo). Experiments shown were repeated three times to confirm reproducibility. 
than that of the control group. The fenofibrate group of LETO rats had a decreased amount of food intake even though their leptin levels appeared lower compared with the control group. Fenofibrate treatment caused hepatomegaly [19]. The increase of liver weight is used for marker for effect of fenofibrate.

We observed that low dose $(30 \mathrm{mg} / \mathrm{kg})$ treatment of fenofibrate, which does not increase the production of ketone bodies, decreased food intake in LETO rats but did not change food intake in OLETF rats. However, a high-dose treatment of fenofibrate decreased food intake in both LETO and OLETF rats [3]. This discrepancy suggests that the anorexigenic effect of fenofibrate may be associated with CCK because the OLETF rats do not have CCK-A receptors [14]. While the effects of fenofibrate are diverse, including anti-atherogenic, anti-diabetic and anti-steatotic effects in rats, its effect on gut hormones, especially on CCK, has not been reported. In this study, we found that the intestinal levels of CCK, as well as $\operatorname{PPAR} \alpha$, were increased in fenofibrate-treated LETO and OLETF rats. We propose that the anorexigenic mechanism of fenofibrate involves the induction of increased CCK production in mucosal cells of the duodenum through the activation of $\operatorname{PPAR} \alpha$. The anorexigenic effect of CCK is predominantly via the vago-vagal reflex rather than direct hormonal action on the satiety center of the CNS [13]. Decreased food intake in the fenofibrate-treated LETO rats may result from increased CCK binding to CCK-A receptors in the small intestine. However, low-dose fenofibrate-treated OLETF rats could not decrease their food intake because of a failure to bind CCK-A receptors and the absence of a change in ketone bodies. In the case of high-dose treatment, fenofibrate induces increased ketogenesis and CCK production, both of which resulted in a reduction of food intake. This result indicates that CCK only induced anorexia with lower doses of fenofibrate treatment, while both CCK and $\beta$-ketone induced anorexia with higher dose of fenofibrate.

In addition, we examined CCK induction by fenofibrate at the cellular level using Caco- 2 cells, a human intestinal epithelial cell line. Caco-2 cells showed dose-dependent expressions of CCK and PPAR $\alpha$ after fenofibrate treatment. Caco- 2 cells showed the increased expression of CCK not only after treatment with fenofibrate but also after treatment with other $\operatorname{PPAR} \alpha$ agonists, bezafibrate and clofibrate. Recently, PPAR $\alpha$ was reported to be an important transcriptional regulator in the small intestine [20]. This finding suggests that $\operatorname{PPAR} \alpha$ may regulate the expression of CCK. Further studies are needed to determine the transcriptional regulatory mechanism of CCK via $\operatorname{PPAR} \alpha$.

This study is the first report that CCK expression is increased by fenofibrate. Fortunately, this finding was possible because we experimented with the physiologically normal LETO rats. There are a few reports of physiologically normal rats, such as Wistar and Sprague Dawley rats, that do not show a reduction of food intake by fenofibrate $[21,22]$. On the contrary, obese-prone mice, such as $\mathrm{db} / \mathrm{db}$ [4] and ob/ob mice [18], showed anorexic effects with fenofibrate treatment. These reports suggest that physiologically normal conditions may be resistant to the effects of fenofibrate due to strain-difference while fenofibrate may be effective in the obese-prone state.

The clinical implication of this study is the possible application of fenofibrate for the treatment of obesity. There were several large-scale, randomized controlled trials using fenofibrate. However, the change in food intake was not in- cluded in the parameters of those trials. The effect of fenofibrate treatment on food intake has not been studied. Thus, a pilot study to evaluate the ability of fenofibrate to reduce food intake in obesity may be necessary. Hypertriglyceridemic patients with mild to moderate obesity would be good candidates for such a study.

In conclusion, a relatively low-dose therapy of fenofibrate decreased food intake in LETO rats by increasing the expression of CCK in duodenum. The increased expression of CCK may be one factor of the anorexigenic effects of fenofibrate.

\section{ACKNOWLEDGEMENTS}

This work was supported by the National Research Foundation of Korea (NRF) funded by the Korean government (MEST) (2010-0001943) and by the Dong-A University Research Fund in 2010.

\section{REFERENCES}

1. Fazio S, Linton MF. The role of fibrates in managing hyperlipidemia: mechanisms of action and clinical efficacy. Curr Atheroscler Rep. 2004;6:148-157.

2. Larsen PJ, Jensen PB, Sørensen RV, Larsen LK, Vrang N, Wulff EM, Wassermann K. Differential influences of peroxisome proliferator-activated receptors gamma and -alpha on food intake and energy homeostasis. Diabetes. 2003;52:2249-2259.

3. Lee HJ, Choi SS, Park MK, An YJ, Seo SY, Kim MC, Hong SH, Hwang TH, Kang DY, Garber AJ, Kim DK. Fenofibrate lowers abdominal and skeletal adiposity and improves insulin sensitivity in OLETF rats. Biochem Biophys Res Commun. 2002;296:293-299.

4. Park CW, Zhang Y, Zhang X, Wu J, Chen L, Cha DR, Su D, Hwang MT, Fan X, Davis L, Striker G, Zheng F, Breyer M, Guan Y. PPARalpha agonist fenofibrate improves diabetic nephropathy in db/db mice. Kidney Int. 2006;69:1511-1517.

5. Srivastava RA, Jahagirdar R, Azhar S, Sharma S, Bisgaier CL. Peroxisome proliferator-activated receptor-alpha selective ligand reduces adiposity, improves insulin sensitivity and inhibits atherosclerosis in LDL receptor-deficient mice. Mol Cell Biochem. 2006;285:35-50.

6. Yamamoto K, Fukuda N, Zhang L, Sakai T. Altered hepatic metabolism of fatty acids in rats fed a hypolipidaemic drug, fenofibrate. Pharmacol Res. 1996;33:337-342.

7. Reddy JK, Hashimoto T. Peroxisomal beta-oxidation and peroxisome proliferator-activated receptor alpha: an adaptive metabolic system. Annu Rev Nutr. 2001;21:193-230.

8. Fisler JS, Egawa M, Bray GA. Peripheral 3-hydroxybutyrate and food intake in a model of dietary-fat induced obesity: effect of vagotomy. Physiol Behav. 1995;58:1-7.

9. Langhans W, Pantel K, Scharrer E. Ketone kinetics and D(-)-3-hydroxybutyrate-induced inhibition of feeding in rats. Physiol Behav. 1985;34:579-582.

10. Arase K, Fisler JS, Shargill NS, York DA, Bray GA. Intracerebroventricular infusions of $3-\mathrm{OHB}$ and insulin in a rat model of dietary obesity. Am J Physiol. 1988;255:R974-981.

11. Bhavsar S, Watkins J, Young A. Synergy between amylin and cholecystokinin for inhibition of food intake in mice. Physiol Behav. 1998;64:557-561.

12. Little TJ, Horowitz M, Feinle-Bisset C. Role of cholecystokinin in appetite control and body weight regulation. Obes Rev. 2005;6:297-306.

13. Konturek SJ, Konturek JW, Pawlik T, Brzozowski T. Brain-gut axis and its role in the control of food intake. $J$ Physiol Pharmacol. 2004;55:137-154.

14. Funakoshi A, Miyasaka K, Shinozaki H, Masuda M, Kawanami T, Takata Y, Kono A. An animal model of congenital defect of 
gene expression of cholecystokinin (CCK)-A receptor. Biochem Biophys Res Commun. 1995;210:787-796.

15. Lee JH, Kim CH, Kim DG, Ahn YS. Microarray Analysis of Differentially Expressed Genes in the Brains of Tubby Mice. Korean J Physiol Pharmacol. 2009;13:91-97.

16. Moran TH, Katz LF, Plata-Salaman CR, Schwartz GJ. Disordered food intake and obesity in rats lacking cholecystokinin A receptors. Am J Physiol. 1998;274:R618-625.

17. Sanders MA, Basson MD. Collagen IV-dependent ERK activation in human Caco-2 intestinal epithelial cells requires focal adhesion kinase. J Biol Chem. 2000;275:38040-38047.

18. Carmona MC, Louche K, Nibbelink M, Prunet B, Bross A, Desbazeille M, Dacquet C, Renard P, Casteilla L, Pénicaud L. Fenofibrate prevents Rosiglitazone-induced body weight gain in ob/ob mice. Int J Obes (Lond). 2005;29:864-871.

19. Nishimura J, Dewa Y, Muguruma M, Kuroiwa Y, Yasuno H,
Shima T, Jin M, Takahashi M, Umemura T, Mitsumori K. Effect of fenofibrate on oxidative DNA damage and on gene expression related to cell proliferation and apoptosis in rats. Toxicol Sci. 2007;97:44-54.

20. Bünger M, van den Bosch HM, van der Meijde J, Kersten S, Hooiveld GJ, Müller M. Genome-wide analysis of PPARalpha activation in murine small intestine. Physiol Genomics. 2007; 30:192-204.

21. Ferreira AV, Parreira GG, Green A, Botion LM. Effects of fenofibrate on lipid metabolism in adipose tissue of rats. Metabolism. 2006;55:731-735.

22. Han Y, Do MH, Kim MS, Seo E, Park MK, Kim DK, Lee HJ, Seo SY. Fenofibrate Reduces Age-related Hypercholesterolemia in Normal Rats on a Standard Diet. Korean J Physiol Pharmacol. 2010;14:77-81. 